Ricketts had made any experiments in regard to the inverted sugar naturally present in raw and refined sugars. This inverted sugar, in most cases optically inactive at ordinary temperature, might have some action on light at $92^{\circ} \mathrm{C}$, and would probably deviate the plane of polarization to the right. He also called attention to the fact that in certain raw sugars, as well as in different products of the retinery which contain naturally inverted sugar, the inverted sugar acts on polarized light in the same direction as cane and grape sugar. Such sugars, if tested after inversion in accordance with Dr. Ricketts' method, would not show zero, but more or less deviation to the right.

Mr. Ricketts said that in his experience the action by inverted sugar was zero at $92^{\circ} \mathrm{C}$.

Mr. Casamajor called attention to the fact that beyond inverted sugar and aconitic acid none of the impurities of cane sugar are known. Beet sugars have been better studied. In them have been found asparagine, asparaginic and citric acids, dextrane, etc. Very likely, substances, the representatives of all these, as aconitic acid is the representative of citric acid, exist in cane sugars, and to them the irregularities are due.

Mr. Eastwick stated that he had also found a difference between the direct and inversion methods of testing in the lower products of the refinery, amounting sometimes to as much as two or three per cent.

The meeting then adjourned.

S. A. GOLDSCHMIDT, Recording Secretary.

\title{
II.-A Method for the Detection of Artificial or Dextro- Glucose in Cane Sugar, and the Exact Determination of Cane Sugar by the Polariscope.
}

By P. DE P. RICKETTS, Ph. D.

Received February 25, 1879.

Having been called upon during the past Summer to examine a number of sugars for artificial or dextro-glucose, I found it necessary to determine some quick and accurate method for the detection of this substance, in the presence of invert and cane sugar. This, $I$ find, can be readily accomplished, by taking advantage of the following facts : 
18t. Artificial or dextro-glucose has a constant effect upon the plane of polarized light, at all temperatures under $100^{\circ} \mathrm{C}$.

$2 d$. Laevulose, or laevo-glucose, does not have a constant action upon the plane of polarized light; the amount of rotation to the left being diminished as the temperature is increased. See Watts' Dictionary of Chemistry, Vol V, page 464.

3d. Invert sugar, being a mixture of $\frac{1}{2}$ dextrose and $\frac{1}{2}$ laevulose, must, if the rotating power of the first to the right be constant, and that of the second to the left diminish as the temperature is increased, be neutral as to its effect upon polarized light, at somewhere near $90^{\circ} \mathrm{C}$. See Watts' Dictionary of Chemistry, Vol v, page 465.

4th. Cane sugar, when acted on by dilute acids, is converted into invert sugar, while dextrose is unaltered.

At the suggestion of Prof. C. F. Chandler, who has favored me with his kind advice throughout, I enclosed the glass tube of the ordinary polariscope in a tin box, so arranged that it could be filled with water, and heated to any desired temperature under $100^{\circ} \mathrm{C}$. I have upon the table, a Ventzke Soleil instrument, the central portion of which has been removed, and a tin box carefully adjusted in its place, which is fitted with a thermometer funnel and draining tube.

The ends of the box are fitted with brass caps, which contain circular pieces of clear plate glass ; these caps screw on, and are perfectly water-tight. The glass tube containing the sugar solution is fitted with a second tube, having a small bore, which is ground in, and is sufficiently long to allow for any expansion of the liquid within, upon heating the apparatus.

To use the instrument, it is only necessary to fill the tube with the sugar solution to be tested, place it in the box, on rests, provided for the purpose, with the small glass tube in a vertical position, pour in distilled water until the box is $\frac{3}{4}$ full, and then apply heat from below, raising the temperature very gradually. I examined first a series of raw and refined sugars of various grades, and found that after clarification, inversion, \&c., they read, almost without exception, zero, at ninety-two degrees Cent.

The effect of the temperature upon the readings can best be shown by example, and I therefore give a few of the results obtained in testing pure cane sugar. 
SUGAR.

TEMPERATURE, CENTIGRADE.

\begin{tabular}{|c|c|c|c|c|c|c|}
\hline No. & Grade. & $60^{\circ}$ & $70^{\circ}$ & $80^{\circ}$ & $90^{\circ}$ & $92^{\circ}$ \\
\hline 1. Cuba Hh & $\mathrm{DS}$ & -11 & -7 & -4.1 & -1 & 0 \\
\hline 2. Muscavai & oo & -10.1 & -7.4 & -5 & -0.5 & +0.2 \\
\hline 3. Mexican & 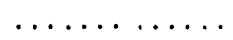 & -11 & -6.8 & -3.5 & -0.8 & 0 \\
\hline 4. REFINED & Cut-loaf..... & -10 & -7.5 & -3.6 & -0.7 & 0 \\
\hline 5. & $\mathrm{X}$ C.. & -10 & -7.5 & -4 & -0.5 & 0 \\
\hline 6. & X Sugar...... & -9.5 & -7 & -4 & -0.5 & +0.3 \\
\hline “ & X Low Grade. & -13.7 & -9.3 & -5.5 & -1.0 & 0 \\
\hline
\end{tabular}

I next examined a number of samples of commercial glucose, and found that after preparing them as in case of the sugars, that they did not vary in their effect upon the plane of polarized light, the same sample of glucose giving a constant rotation to the right, at all temperatures under $100^{\circ} \mathrm{C}$.

I give below a few of the readings obtained from some of the samples tested, which did not, however, contain in each case the same amount of chemically pure glucose, as that determined by Fehling's test.

SAMPLE.

Marks, etc.
TEMPERATURE, CENTIGRADE.

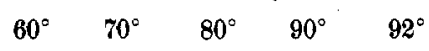

No. 1. $\left\{\begin{array}{c}\text { Corn Guvcose, } \\ \text { Am. Grape Sugar Co. }\end{array}\right\}+87+87+87+87+87$ \&c. “2. $\left\{\begin{array}{c}\text { Glccose, } \\ \text { Locality Unknown. }\end{array}\right\}+35+35+35+34.5+34.3 \& c$. “ 3. Dry Grape Sugar. $+56+56+56+56+56 \quad \&$ c. “4. $\left\{\begin{array}{c}\text { Grape Stgar, } \\ \text { Tromsdorff. }\end{array}\right\}$ $+35+35+35+35+35 \quad$ \&c.

Nos. 2 and 4 contained the same amount of chemically pure glucose.

By observing a number of samples of commercial glucose, $I$ found the average rotation to the right at $92^{\circ} \mathrm{C}$. to be 87 divisions of the scale of the instrument, when the sample tested contained 63 per cent. by Frehlings test, of chemically pure glucose. Hence, if $26.048 \mathrm{gms}$. be the amount taken for observation, $26.048 \times \frac{63}{100}$ $\div 87 \times 100=18.864$ gms., is the amount of dry, chemically pure, glucose necessary to read 100 divisions on the scale, or each division is equal to $0.1886 \mathrm{gms}$. of chemically pure glucose.

Having established my data as to the action of invert sugar and dextro-glucose upon polarized light, and the value of the divisions on the scale of the instruments, I made a series of mixtures of commer- 
cial glucose, with cane sugar of various grades, and found I could determine with accuracy the amount of glucose added, even where the nixture contained as little as one and one-half per cent. of commercial glucose. The following readings, made with two mixtures, prepared by my assistant, and submitted to me without my knowing the percentage of adulteration, will, I think, be sufficient to illustrate the method and prove its value.

SAMPLE.

Contained Chemically

TEMPERATURE, CENTIGRADE.

\begin{tabular}{ccccccc}
\multicolumn{9}{c}{ Pure Glucose. } & $60^{\circ}$ & $70^{\circ}$ & $80^{\circ}$ & $90^{\circ}$ & $92^{\circ}$ \\
No. 1. & 6.6 grms. & +26.7 & +28 & +32 & +34 & +35 \\
“ 2. & 8.2 " & +38 & +41 & +41.9 & +42.8 & +43
\end{tabular}

ROTATION OBSERVED. VALUE OF SCALE. GRMS, FOUND.

$\begin{array}{ccccc}\text { No. 1. } & +35 & \times & 0.1886 & = \\ \text { " } 2 . & +43 & \times & 0.1886 & \end{array}$

Of course, in testing the mixtures, care was taken to invert all the cane sugar before observation in the instrument.

By weighing out $18.86 \mathrm{gms}$. of the invert sugar present, the second will give the cane sugar and dextro-glucose; the third, the dextroglucose.

The temperature given, $92^{\circ} \mathrm{C}$, refers to the water bath; the temperature of the solution within the tube, may be slightly lower, but as the same apparatus has been employed throughout, the results are comparative, and will hold true.

To adjust the instrument for my experiments, I test it with, first, a solution of pure cane sugar ; second, a solution of pure cane sugar inverted; third, a solution of standard commercial glucose, and fourth, a mixture containing a known percentage of pure glucose.

The first solution should read 100 ; the second zero at $92^{\circ} \mathrm{C}$; the third, indicate a constant dextro-rotation, and the fonrth, read to the right. After inversion, according to the amount of dextro-glucose added, when observed at $92^{\circ} \mathrm{C}$, , or the temperature at which the solution of invert sugar read zero, the amount of dextro-glucose contained in the sample to be tested will read percentage on the scale, and the calculation given above be avoided.

In order to determine the effect of raising the temperature on the readings of a solution of cane sugar, I took 26.048 grms., clarified, and observed it in the instrument. I found that the reading at $92^{\circ} \mathrm{C}$. would be slightly less than at the ordinary temperature, especially if the sugar was in the slightest degree acid; but if a slight excess of carbonate of soda or lime be added to the sugar solution before fill- 
ing the polariscope tube, the readings would be nearly const unt. Hence, to determine invert cane sugar and dextro-glucose in a sample, observe first, at-say $25^{\circ} \mathrm{C}$; ; second, at $92^{\circ} \mathrm{C}$.; without inverting; third, invert and read at $92^{\circ} \mathrm{C}$. The first observation would give us the cane sugar and the dextrose less the left rotation due to laevulose.

I am still experimenting on sugars of various grades, and may be able to give you in another paper some further details.

In conclusion I wish to express my thanks to my assistant, Mr. C. L. Constant, who has aided me materially in the experimental work necessary for the preparation of this paper.

\section{III.-Prochenings.}

Regular Meeting, February 16, 1879.

Tre meeting was called to order at 8:15 o'clock, Vice-President Leeds in the chair. The minutes of the last meeting were read and adopted.

The Board of Directors reported as follows:

At a meeting held January 16, 1879-Present, Messrs. Leeds, Nichols, Casamajor, Miller, Waller, Endemann and Goldschmidt.

The Treasurer reported a balance of $\$ 984.79$.

The following bills were audited and ordered to be paid: T. J. Fay, $\$ 9.00$; G. E. Stechert, $\$ 19.65$.

On motion of the Treasurer it was resolved to appoint a committee to mature a plan of action for the collection of the amount due the Society for arrears of dues, and to report the names of nembers to be dropped from the rolls of the Society for such nou-payment. The chair appointed as committee Messrs. Casamajor, Nichols and Goldschmidt.

Resolved, That no one should be considered a member of the Society, or receive the proceedings or their publications, until he shall have paid his initiation fee and dues for the current year.

Resolved, That the Librarian hereafter send out the proceedings.

Resolved, That the Treasurer be empowered to make such arrangements in regard to re-engaging the rooms of the Society as he may deem proper.

At a neeting of the Board of Directors, held February 6, 1879 Present, Messrs. Leeds, Goldmark, Endemann, Miller, Nichols, Waller, Casamajor, Eastwick and Goldschmidt. 